\title{
Investigation and Design of Wireless Power Transfer System for Autonomous Underwater Vehicle
}

Dou, Yi; Zhao, Dehua; Ouyang, Ziwei; Andersen, Michael A. E.

Published in:

Proceedings of 2019 IEEE Applied Power Electronics Conference and Exposition (APEC)

Link to article, DOI:

10.1109/APEC.2019.8721879

Publication date:

2019

Document Version

Peer reviewed version

Link back to DTU Orbit

Citation (APA):

Dou, Y., Zhao, D., Ouyang, Z., \& Andersen, M. A. E. (2019). Investigation and Design of Wireless Power Transfer System for Autonomous Underwater Vehicle. In Proceedings of 2019 IEEE Applied Power Electronics Conference and Exposition (APEC) (pp. 3144-3150). IEEE. https://doi.org/10.1109/APEC.2019.8721879

\section{General rights}

Copyright and moral rights for the publications made accessible in the public portal are retained by the authors and/or other copyright owners and it is a condition of accessing publications that users recognise and abide by the legal requirements associated with these rights.

- Users may download and print one copy of any publication from the public portal for the purpose of private study or research.

- You may not further distribute the material or use it for any profit-making activity or commercial gain

- You may freely distribute the URL identifying the publication in the public portal 


\title{
Investigation and Design of Wireless Power Transfer System for Autonomous Underwater Vehicle
}

\author{
Yi Dou, Dehua Zhao, Ziwei Ouyang and Michael A.E. Andersen \\ Department of Electrical Engineering \\ Technical University of Dennark \\ Kgs. Lyngby, Denmark \\ zo@elektro.dtu.dk
}

\begin{abstract}
With the development of wireless power transfer (WPT) technology, it is possible to transfer power to the batteries without plug-in cables and human interaction for autonomous underwater vehicles (AUVs), taking advantage of high safety, high reliability and unattended capability. However, when implementing the WPT system under the seawater environment, the electrical properties of seawater including the permittivity and the conductivity cause a significant changing in the parasitics of winding coils underwater. The seawater, which owns higher permittivity and conductivity compared to the air, not only causes extra parasitic capacitance to coils but also conducts extra eddy current loss, and thus reduces the system efficiency. In this paper, the characteristics of winding coils underwater are investigated and an optimized design methodology for underwater WPT system with series-series (SS) compensation is proposed. A 200-W underwater WPT prototype is built and experimentally verifies the analysis for the coils and the optimized design approach. The experimental demonstration also shows the system efficiency comparison between the air, the water, and the seawater environments.
\end{abstract}

Index Terms-Underwater wireless power transfer, inductive power transfer, Series-Series compensation, optimized design, autonomous underwater vehicles

\section{INTRODUCTION}

For autonomous underwater vehicles (AUVs), the capacity of batteries is the critical factor which determines their mission lifetime. Nevertheless, it is of great difficulty to replace the batteries or use plug-in battery chargers for the AUVs to prolong the operation time, unlike terrestrial vehicles because of operating costs as well as human safety issues. Currently, the emergence of wireless power transfer (WPT) offers a better choice for transmitting power to the AUVs [1, 2, 3, 4].With the WPT technology for the underwater conditions, several benefits can be achieved including lower operating costs due to corrosion and short circuit, improving operational safety and considerably reducing manual risks. Nowadays, the WPT has already been applied in many applications to realize over-air wireless power transmission. In the smallpower field, the WPT systems based on microwave technology or inductive power transfer (IPT) are capable of transmitting power between centimeter-sized distance and has been extensively applied in consumer electronics especially smart phones [5][6]. Besides, recent research for inductive power transfer has verified the feasibility in the higher power applications such as electrical vehicles $[7,8,9]$.
However, unlike the terrestrial applications, the WPT underwater is facing significant challenges caused by the electrical properties of water environments. The freshwater and the seawater have the relative permittivity of 80 and 85 respectively (which of the air is 1), and this attribute would significantly influence the modeling of winding coils underwater. The parasitic capacitances over the winding coils under the air conditions are usually neglected for its lower value and insignificant contribution for coils impedance. Whereas for underwater coils the parasitic capacitance would move the resonance frequencies of coil impedance to lower frequencies, and therefore affect the compensator network and the system operation frequency. Moreover, the seawater is remarkably more conductive than the air and the freshwater. Thus, the magnetic field produced by the transmitter and receiver coils would create appreciable eddy current within the water, which leads to the extra power loss during power transmission.

In this paper, the underwater wireless power transfer system is investigated and especially the characteristics of winding coils underwater environment are analyzed. Based on the investigation, the design considerations for the WPT system underwater are presented and an optimized design methodology is proposed to achieve the maximum system efficiency. A 200W underwater WPT prototype is built, which is demonstrated in the air, the fresh-water and the sea-water respectively. The optimized design approach is verified by experimental results and its peak efficiency can achieve at $94.3 \%$ in the seawater environment.

\section{Circuit OPERATION AND Underwater CoIL CHARACTERS}

1) Operation principle and Series-series compensation for IPT: The basic structure for inductive power transfer consists of an AC source, two coupled coils named transmitter coil (Tx) and receiver coil (Rx), and the load, as illustrated in Fig. 1. As the AC source giving a current excitation to the coil Tx, the magnetic flux $\psi 12$ and $\psi 11$ are generated by the Tx and part of the flux $(\psi 12)$ would be coupled with the the $\mathrm{Rx}$ coil. If a close-loop electrical path is build by the load connected to the Rx, for example a resister, an induced current would be generated in the load, which means the power from the AC source is transferred to the load. It is noticed that with the induced current goes through the Rx coil, the 
magnetic flux $\psi 21$ and $\psi 22$ would be generated and coupled with magnetic flux $\psi 12$. Therefore, the Tx coil and the Rx coil are magnetically coupled and accordingly create the electrical interaction.

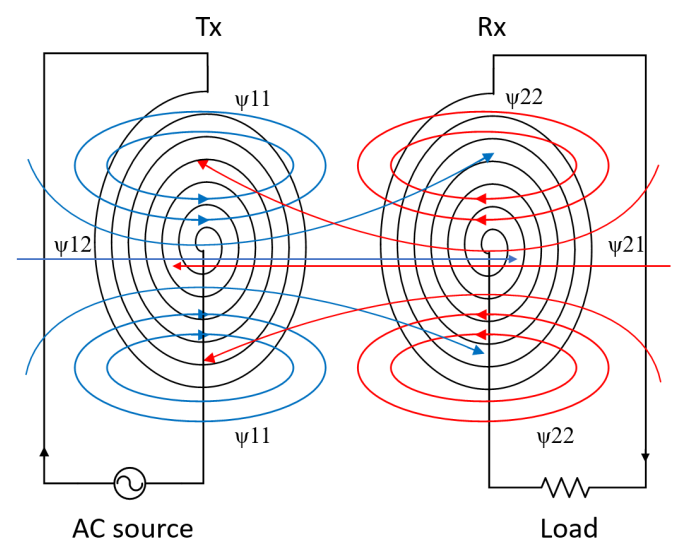

Fig. 1. Fundamental operation with two-coil WPT system

In the over-air environment, the two coupled coils can be electrically modelled in three types: transformer model, coupled inductor model and T-model, as shown in Fig. 2. The coupled coils in the WPT system can be regarded as a loose-coupled transformer, whose leakage inductance is in the same order of its magnetizing inductance. However, the energy from the AC source cannot be entirely transferred from the Tx coil to the Rx coil because a large amount of energy would be stored in the primary leakage inductance. Thus, adding capacitors to form a resonant compensation network with the leakage inductance is a must to enhance the power transfer capability for the WPT system [10].

Series-Series compensation is the most widely used topology in IPT system, which has load-independent current output characteristic and high reliability with coil misalignment [11, $12,13,14]$. A typical WPT system with S-S compensation, consisting of the DC source, the inverter, the primary compensation capacitor, the Tx and Rx coils, the secondary compensation capacitor, the rectifier and the load, is illustrated in Fig. 3(a) and its equivalent circuit with the T-model is shown in Fig. 3(b).

The fundamental operation of the S-S compensation topology can be described as $[15,16,17]$,

$$
\left[\begin{array}{c}
\dot{U}_{1} \\
\dot{U}_{2}
\end{array}\right]=\left[\begin{array}{cc}
j \omega L_{1}+\frac{1}{j \omega C_{p}}+R_{1} & j \omega L_{m} \\
L_{m} & j \omega L_{2}+\frac{1}{j \omega C_{s}}+R_{2}
\end{array}\right]\left[\begin{array}{c}
\dot{i}_{1} \\
\dot{i}_{2}
\end{array}\right]
$$

where $L_{1}$ equals $L_{p}+L_{m}$ while $L_{2}$ equals $L_{s}+L_{m}$, and $L_{p}, L_{s}$ are leakage inductance of primary and secondary coils respectively while $L_{m}$ is the mutual inductance between two coupled coils; $\omega$ is the angular frequency; $C_{p}$ and $C_{s}$ are the value of compensation capacitance; $R_{l}$ is the equivalent load resistance, which can be calculate by fundamental harmonic approximation (FHA) with different configuration of rectifier; and $R_{1}$ and $R_{2}$ are the equivalent series resistance of the

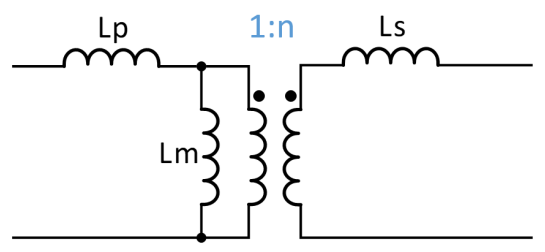

(a) Transformer model

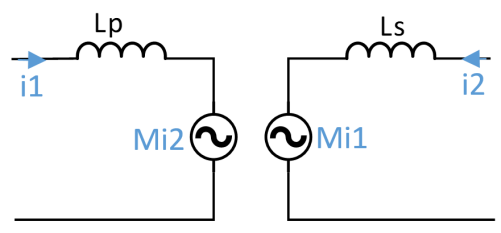

(b) Mutual inductance model

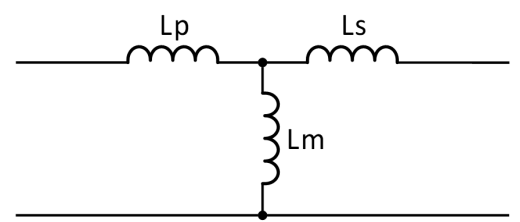

(c) T-type model

Fig. 2. Equivalent electrical model for a pair of coupled coil

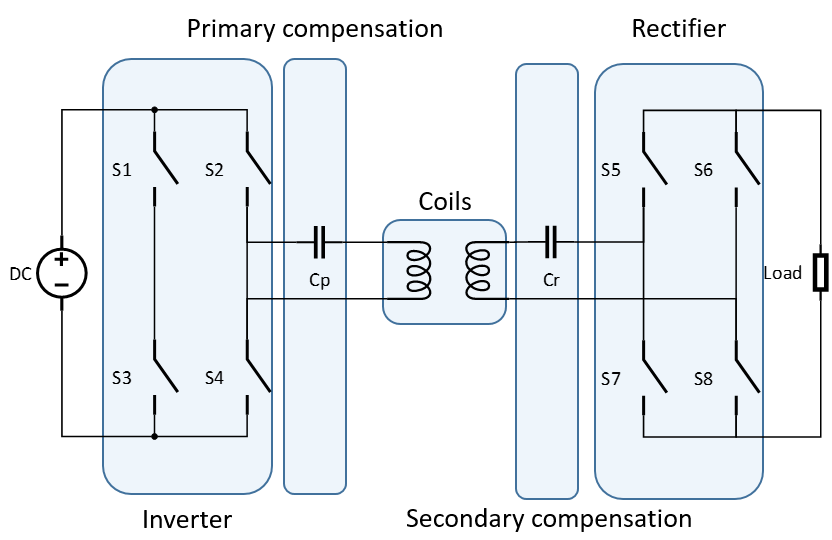

(a) Structure diagram of WPT system with S-S compensation

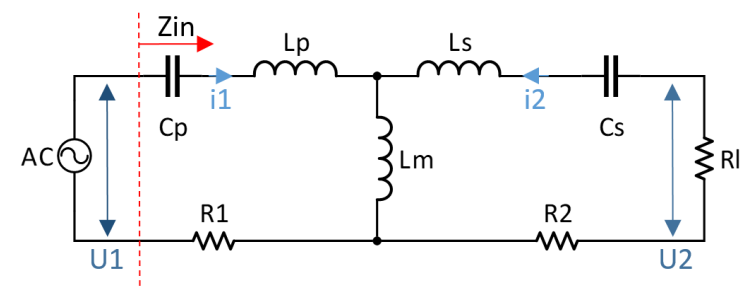

(b) Equivalent circuit of S-S compensation WPT system with T-type model

Fig. 3. Structure of WPT system with S-S conpensation

primary and secondary coils. To ensure that both primary side and secondary side working at the same resonant frequency and realize achieve the maximum power transfer capability 
for the system, the series compensation capacitors $C_{p}$ and $C_{s}$ are designed to compensate with $\left(L_{p}+L_{m}\right)$ and $\left(L_{s}+L_{m}\right)$ correspondingly. Thus, the relationship between switching frequency and parameters of resonant tank can be described as

$$
f=\frac{1}{2 \pi \sqrt{\left(L_{p}+L_{m}\right) C_{p}}}=\frac{1}{2 \pi \sqrt{\left(L_{s}+L_{m}\right) C_{s}}}
$$

In practical design, the minimum equivalent series resistance (ESR) of coils is preferred to reduce the power loss. Thus, in order to simplify the analysis, the ESRs are neglected and the input impedance, current and voltage in the system can be described as:

$$
\left\{\begin{array}{cc}
Z_{i n}= & \frac{\omega^{2} L_{m}^{2}}{R_{l}} \\
\dot{i}_{1}= & \frac{\dot{U}_{1} R_{l}}{\omega^{2} L_{m}^{2}}=\frac{\dot{U}_{2}}{j \omega L_{m}} \\
\dot{i}_{2}= & \frac{\dot{U}_{1}}{j \omega L_{m}} \\
\dot{U}_{2}= & -\frac{\dot{U}_{1} R_{l}}{j \omega L_{m}}
\end{array}\right.
$$

where $Z_{\text {in }}$ is the input impedance of the system, as illustrate in Fig. 3; $\dot{U}_{1}$ is the output voltage of the inverter; $\dot{U}_{2}$ is the voltage of the load; $\dot{i}_{1}$ and $\dot{i}_{2}$ are the current in the Tx and Rx. It can be found equation (3) that when operating at resonant frequency, WPT system with S-S compensation can be regarded as a voltage-controlled current source; and combined with equation (2), the system's resonant frequency is depended on the parameters of coils and compensation capacitors. Besides, the input impedance without the imaginary part means that no harmonic current is needed to build and maintain magnetic flux between two coils and thus a high transmission efficiency could be realized. For a specified transfer distance, one coil configuration has its corresponding self inductance and coupling factor. With a specified voltage gain and load condition, the efficiency of entire system can be optimized by choosing switching frequency and its corresponding compensation capacitance. Thus, in order to optimize the design for high efficiency and high reliability for components, a trade-off between coil configuration and voltage stress on compensation capacitors must be considered.

2) Underwater Coils Character: Though the S-S topology utilizes coupled magnetic field to achieve power transfer from the transmission coil to the receiver coil, whose operation is hardly influenced directly by the seawater environment, the characters of underwater coils would shift compared with over-air coils because of the higher permittivity and high conductivity of the seawater. The permittivity of fresh water and seawater is between 80 and 85 , while the permittivity of air is 1. Thus, extra parasitic capacitance between wires and wires for two coils would occur and produce a low-impedance path for high-frequency current. In order to investigate the influence from the extra parasitic capacitance, the impedance of a series of underwater coils are measured by the impedance analyzer to observe the shift of its self-resonance. An highfrequency excitation is added on the coils and swept from 40 $\mathrm{kHz}$ to $5 \mathrm{MHz}$. And a comparison of impedance measurement results from the coil build by 29 turns/ $60 * 0.1 \mathrm{~mm}$ diameter litz wire are shown in Fig. 4. It can be found that the self-resonant frequency of the over-air coils is $2.69 \mathrm{MHz}$ as shown in Fig. 4(a). As shown in Fig.4 (b), the impedance of the underwater coils shows a totally different characters. The self-resonance frequency and a high-impedance peak disappear because extra parasitic capacitance between the Tx coil and Rx coil causes a low impedance path for AC current.

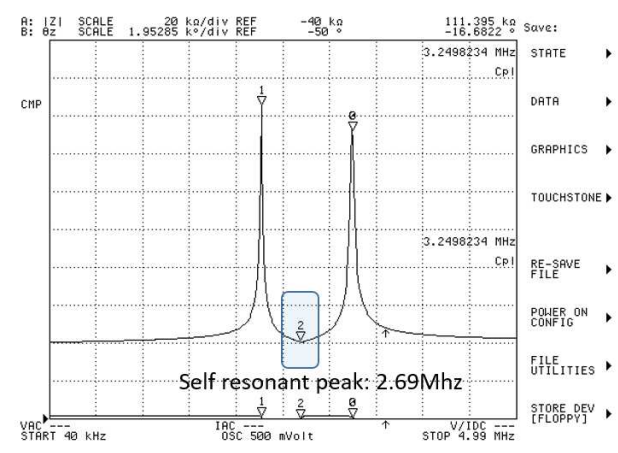

(a) Air condition

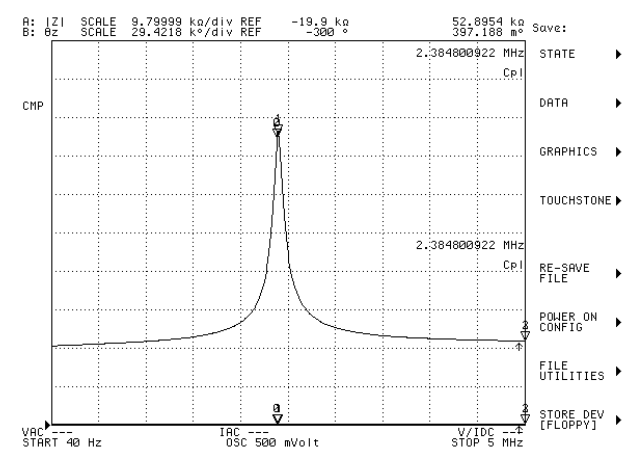

(b) Seawater condition

Fig. 4. Impedance measurement results of coils

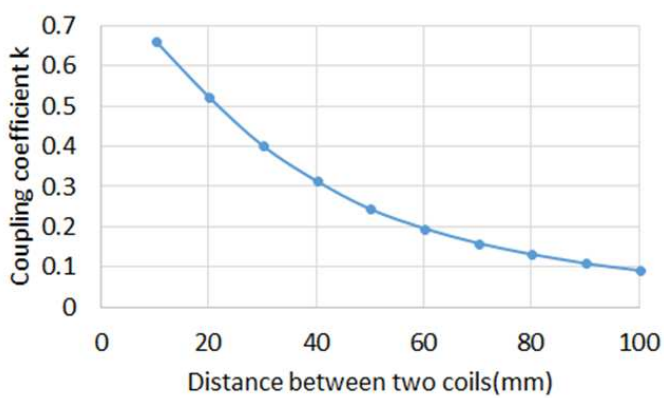

Fig. 5. Coupling coefficient of underwater coil with various distance 29 turns with inner $50 \mathrm{~mm} / 60 * 0.1 \mathrm{~mm}$ litz wire

Comparing to the air whose conductivity is approximately zero, fresh water has a conductivity of $0.1 \mathrm{~S} / \mathrm{m}$ while sea water has an even higher conductivity of around $4 \mathrm{~S} / \mathrm{m}$. Thus, extra eddy current loss in the seawater would reduce the system efficiency [18]. Though with excellent heat conduction capa- 
bility, the temperature rise will not destroy the components or the coils, a high efficiency is hard to achieve especially with a large transmission distance.

In addition, the coupling coefficient of coils are measured by the impedance analyzer in the seawater condition. The results in Fig. 5 illustrate that with a constant number of turns the coupling coefficient decreases with increasing of the transmission distance, which shows similar with the over-air condition. The coupling coefficient is able to get 0.4 at $30 \mathrm{~mm}$ transmission distance for the coil which consists of 29 turns with inner diameter of $50 \mathrm{~mm}$ and build by $60 * 0.1 \mathrm{~mm}$ litz wire, as shown in Fig. 7.

Take these issues into consideration, when designing an underwater WPT system, the characters of coils must be evaluated firstly as the reference for switching frequency selection. And the extra power loss from the eddy current in the water must be considered and compensated.

\section{Optimal Parameter Design FOR 200W UNDERWATER WPT SYSTEM}

Optimization design for efficiency of an underwater WPT system necessitates many trade-offs and iterations with the configuration of coils and power loss estimation. Once the design specifications of the system is determined the choice of compensation of series capacitors and resonant frequency are constrained in the optimization to achieve higher efficiency. The flow chat of proposed optimization method is shown in Fig. 6. The fundamental reference of the design is the character of underwater coils from impedance measurement. The energy losses of MOSFETs from inverter, diodes from rectifier, winding loss from coils and ESR loss from compensation capacitors are considered and calculated as the function of switching frequency and worked as the final reference of design. The proposed optimization routine is described in the following steps:

Step 1 Measure inductance and resistance of coil The coils inductance and resistance are measured by impedance analyzer with sweeping number of turns and frequency. In the design the initial inner diameter of coils is selected as $50 \mathrm{~mm}$ and the number of turns is swept from 27 to 37 turns. The transmission distance is set as $30 \mathrm{~mm}$ in the seawater environment.

Step 2 Calculate corresponding resonant frequency The voltage gain for the system at resonant frequency is given by

$$
\left|\frac{\dot{U}_{2}}{\dot{U}_{1}}\right|=\frac{R_{l}}{\omega L_{m}}
$$

And according to (4), the switching frequency corresponding to different number of turns from the step 1 can be calculated. The switching frequency must be lower than one tenth of the self-resonant frequency otherwise lower number of turn must be adopted.

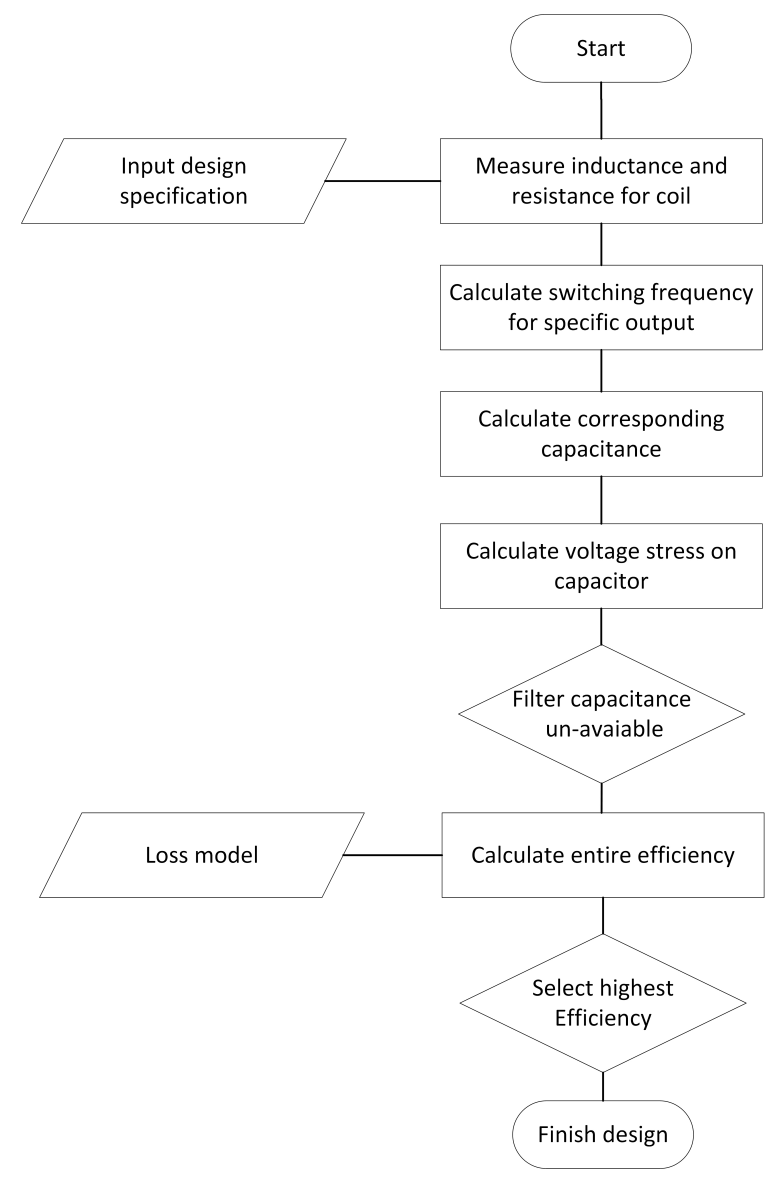

Fig. 6. Flow chat of the proposed efficiency optimization approach

Step 3 Calculate corresponding compensation capacitance With the switching frequency kept the same as the resonance frequency the corresponding compensation capacitance can be calculated by equation (2). After this step the parameters of resonant tank with its winding configuration can be decided.

Step 4 Calculate voltage stress on capacitors

The voltage stress on capacitors is another limitation for higher efficiency and high reliability of the system. Since in every duty cycle, the power stored in coils is equal to the power that compensated by capacitors. The voltage stress on capacitors can calculated by

$$
\left|V_{c}\right|=\frac{R_{l}}{\omega L_{m}} \frac{\left|\dot{U}_{1}\right|}{k^{2}}
$$

Step 5 Calculate estimated power loss and select optimized point

Total power loss on coils, compensation capacitors and switches is calculated with sweeping switching frequency and the design with lower power loss can be selected as the optimized point for the system. In this design the calculated power loss is shown in Table.I. and the number of turns of 29 is selected for the design with lowest power loss. A power 
TABLE I

PARAMETER SWEEPING RESULTS FOR OPTIMIZED DESIGN

\begin{tabular}{lllllll} 
Number of turns & $\begin{array}{l}\text { Resonant } \\
\text { frequency }(\mathrm{kHz})\end{array}$ & $\begin{array}{l}\text { Compensation } \\
\text { capacitance }(\mathrm{nF})\end{array}$ & $\begin{array}{l}\text { Voltage stress on } \\
\text { cap. }(\mathrm{V})\end{array}$ & $\begin{array}{l}\text { Mutual } \\
(\mathrm{uH})\end{array}$ & $\begin{array}{l}\text { inductance } \\
\text { Couple } \\
\text { coefficient }\end{array}$ & \begin{tabular}{l} 
Power loss (W) \\
\hline 37
\end{tabular} \\
\hline 58.82 & 28.81 & 293.8 & 108.23 & 0.425 & 9.535 \\
36 & 63.15 & 26.30 & 300 & 100.80 & 0.416 & 9.46 \\
34 & 67.04 & 24.55 & 302.3 & 94.96 & 0.413 & 9.75 \\
33 & 72.35 & 22.63 & 305.1 & 87.99 & 0.410 & 8.73 \\
32 & 77.79 & 20.70 & 309.8 & 81.83 & 0.404 & 8.37 \\
31 & 83.67 & 18.89 & 315.8 & 76.09 & 0.396 & 8.32 \\
30 & 89.78 & 17.37 & 319.7 & 70.90 & 0.390 & 8.28 \\
29 & 97.86 & 15.80 & 322.3 & 65.04 & 0.388 & 7.811 \\
28 & 105.68 & 14.38 & 327.7 & 60.24 & 0.382 & 7.64 \\
27 & 115.01 & 12.92 & 334.6 & 55.35 & 0.373 & 7.72 \\
\end{tabular}

loss model used in power loss calculation is presented in the appendix.

\section{EXPERIMENTAl Results AND Discussion}

Following the optimized design presented in section III, the a couple of coils is built by litz wires with plastic supporter and screws, as shown in Fig. 7 and a $200 \mathrm{~W}$ underwater WPT prototype is set up, as shown in Fig. 8. A water tank with customized supporter could provided distance adjustment as well as water proofing for the coils. The detailed parameters of the prototype is given in Table II. The compensation capacitance is selected as $15 \mathrm{uF}$ to match the commercially available ceramic capacitors and correspondingly the switching frequency is adjusted to be $103.5 \mathrm{kHz}$.

TABLE II

PARAMETERS OF 200W UNDERWATER WPT PROTOTYPE

\begin{tabular}{|c|c|}
\hline & Value \\
\hline Inverter & IRFH5215/Full bridge \\
\hline Rectifier & FSV10150V/Full bridge \\
\hline Gate Driver & $\mathrm{Si} 8273$ \\
\hline \multirow{2}{*}{ Primary coil } & 29 turns / 60*0.1mm Litz wire \\
\hline & $156.7 \mathrm{uH}$ \\
\hline \multirow{2}{*}{ Secondary coil } & 29turns / 60*0.1mm Litz wire \\
\hline & $157.4 \mathrm{uH}$ \\
\hline \multirow{3}{*}{ Primary compensation } & C2012NP02W332J 3.3nF/450V * 4 \\
\hline & CGA4F4NP02W $1.8 \mathrm{nF} / 450 \mathrm{~V} * 1$ \\
\hline & TDK \\
\hline \multirow{3}{*}{ Secondary compensation } & C2012NP02W332J 3.3nF/450V * 4 \\
\hline & CGA4F4NP02W $1.8 \mathrm{nF} / 450 \mathrm{~V} * 1$ \\
\hline & TDK \\
\hline Switching frequency & $103.5 \mathrm{kHz}$ \\
\hline
\end{tabular}

The open-loop test is carried out for the prototype to verify the power transmission capability and a comparison among over-air condition, under-water condition and under-seawater is made to investigate the influence brought by seawater environment. The input and output voltage are both set as 100

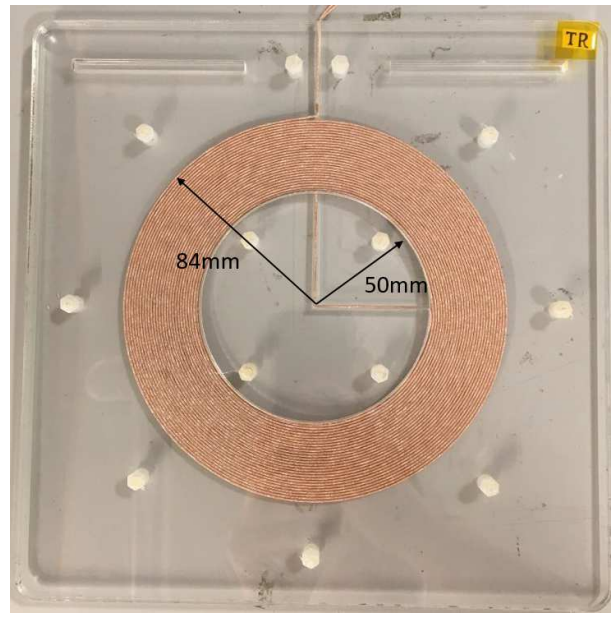

Fig. 7. Underwater coil built by litz wire

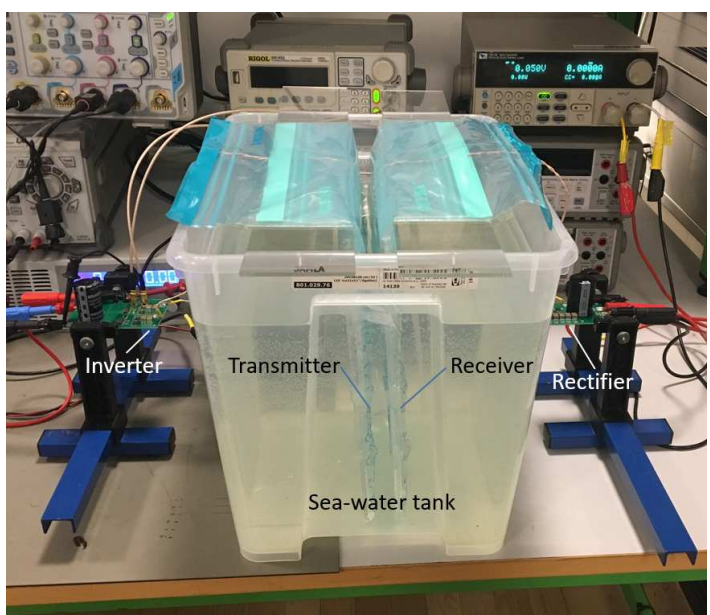

Fig. 8. 200W Underwater wireless power transfer system setup

$\mathrm{V}$ and the efficiency against transmission distance is given in Fig. 9(a). For an optimize-design underwater system, the efficiency is kept within a flat region from $100 \mathrm{~W}$ to 200 $\mathrm{W}$ at difference transmission distance and the peak efficiency 


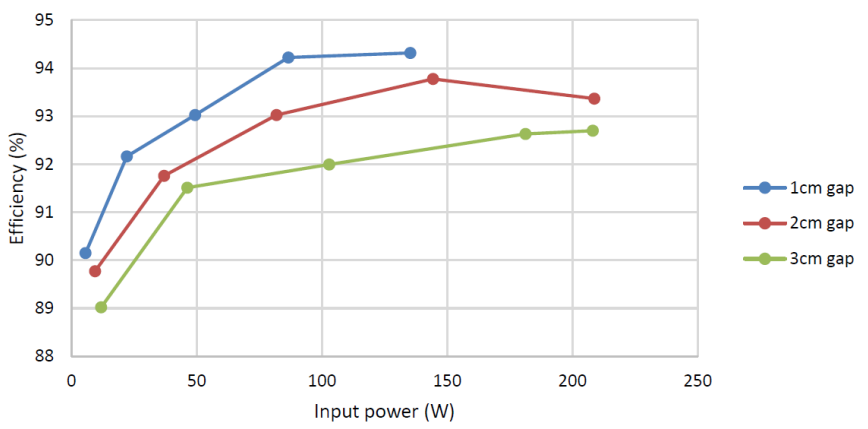

(a) Underwater system efficiency with difference transmission distance

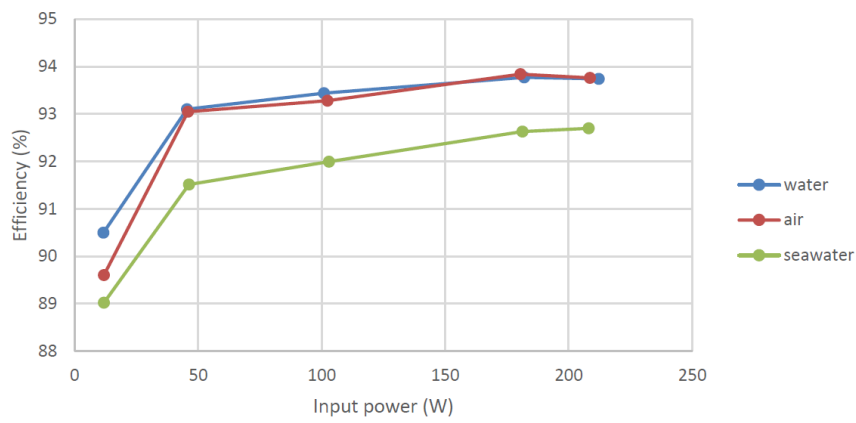

(b) Efficiency comparison with $30 \mathrm{~mm}$ transmission distance

Fig. 9. Efficiency measurement results of prototype

achieved $94.5 \%$. The efficiency achieves $92.3 \%$ with $30 \mathrm{~mm}$ transmission distance in the seawater condition. Generally the power efficiency drop with increasing of transmission distance and drop rapidly as it approach $25 \%$ of rated power.

The efficiency comparison is also conducted in different transmission environment. Fig. 9(b) shows the efficiency of system in over-air condition, under-water condition and underseawater condition at $30 \mathrm{~mm}$ transmission distance. At different transmission power, the efficiency of over-air condition and under-water condition is identical but both higher than that of under-seawater condition. At the operating point $200 \mathrm{~W}$ output power and $100 \mathrm{~V}$ output voltage, the total system loss in under-seawater condition was found to be approximately $1 \%$ lower that other two condition, which is brought by the large conductivity and eddy current loss of seawater.

\section{CONCLUSION}

This paper presents the investigation and design of underwater WPT system for AUV charging application. The characters of underwater coils are investigated with impedance measurement and the influence caused by extra parasitic capacitors and conductive seawater environment are discussed. With the measurement results of underwater coils, an optimized design approach for underwater S-S compensation topology is proposed and utilized to design a $200 \mathrm{~W}$ IPT system. A 103.5 $\mathrm{kHz}$ underwater WPT system is built and tested in underseawater condition and its power transfer capability of $200 \mathrm{~W}$ is achieved. The experimental results verify the proposed optimized design approach and an efficiency comparison among over-air condition, under-water condition and under-seawater condition is conducted.

\section{ACKNOWLEDGMENT}

This work was support by DTU Orients Fund.

\section{APPENDIX: POWER LOSS MODEL OF THE SYSTEM}

The appendix provides the loss model which is used to estimate the power loss and select the optimized point for the system in section III.

The conduction loss from each MOSFET in inverter can be calculated by:

$$
P_{\text {conduction }}=I_{R M S}^{2} R_{D S(\text { on })}
$$

where $I_{R M S}$ is the RMS value of the current on a MOSFET; $R_{D S(o n)}$ is the drain-source conduction resistance of the MOSFET. The turn-on loss of the switches can be calculated by:

$$
P_{\text {turn-on }}=\frac{1}{2} C_{o s s} V_{d s(o n)} f_{s}
$$

where $V_{d s(o n)}$ is the drain-to-source voltage of the MOSFET before it is turned on; $C_{o s s}$ is the output capacitance of the MOSFET and $f_{s}$ is the switching frequency. The The turn-off loss of the switches can be calculated by [19]:

$$
P_{\text {turn-off }}=\frac{i_{\text {off }}^{2} t_{\text {off }}^{2}}{48 C_{\text {oss }}} f_{s}
$$

where $i_{\text {off }}$ is the current on the MOSFET when it is turned off and $t_{o f f}$ is the fall time of the current. Since at resonance frequency the current on coils is sinusoidal thus the winding loss on coils can be calculated by

$$
P_{\text {coil }}=i_{l}^{2} R_{a c, f}
$$

where $i_{l}$ is the RMS value of current on a coil and $R_{a c, f}$ is the $\mathrm{AC}$ resistance at specific frequency, which can be measured by the impedance analyzer. The power loss on a diode from the rectifier is given by

$$
P_{D}=V_{F} i_{a v e}
$$

where $V_{F}$ is the forward voltage of the diode when it conducts and $i_{\text {ave }}$ is the average value of current on the diode. Finally, the power loss on compensation capacitors can be calculated by

$$
P_{\text {cap }}=I_{\text {cap }}^{2} R_{\text {esr }}
$$

where $I_{c a p}$ is the RMS value of current on capacitors and $R_{e s r}$ is the equivalent series resistance of the capacitors. In practical if the compensation capacitor consist of several capacitors in parallel, the ESR should be calculated as several resistors in parallel. 


\section{REFERENCES}

[1] C. C. Mi et al. "Modern Advances in Wireless Power Transfer Systems for Roadway Powered Electric Vehicles". In: IEEE Transactions on Industrial Electronics 63.10 (Oct. 2016), pp. 6533-6545.

[2] W. Niu, W. Gu, and J. Chu. "Analysis and experimental results of frequency splitting of underwater wireless power transfer". In: The Journal of Engineering 2017.7 (2017), pp. 385-390.

[3] T. Assaf, C. Stefanini, and P. Dario. "Autonomous Underwater Biorobots: A Wireless System for Power Transfer". In: IEEE Robotics Automation Magazine 20.3 (Sept. 2013), pp. 26-32.

[4] T. M. Hayslett, T. Orekan, and P. Zhang. "Underwater wireless power transfer for ocean system applications". In: OCEANS 2016 MTS/IEEE Monterey. Sept. 2016, pp. 1-6.

[5] K. Wan et al. "Passive Radio-Frequency Repeater for Enhancing Signal Reception and Transmission in a Wireless Charging Platform". In: IEEE Transactions on Industrial Electronics 61.4 (Apr. 2014), pp. 1750-1757.

[6] J. Feng, Q. Li, and F. C. Lee. "Omnidirecitional wireless power transfer for portable devices". In: 2017 IEEE Applied Power Electronics Conference and Exposition (APEC). Mar. 2017, pp. 1675-1681.

[7] W. Li et al. "Integrated $L C C$ Compensation Topology for Wireless Charger in Electric and Plug-in Electric Vehicles". In: IEEE Transactions on Industrial Electronics 62.7 (July 2015), pp. 4215-4225.

[8] J. Deng et al. "Compact and Efficient Bipolar Coupler for Wireless Power Chargers: Design and Analysis". In: IEEE Transactions on Power Electronics 30.11 (Nov. 2015), pp. 6130-6140.

[9] M. Ghorbani Eftekhar et al. "Efficiency Study of Vertical Distance Variations in Wireless Power Transfer for E-Mobility". In: IEEE Transactions on Magnetics 52.7 (July 2016), pp. 1-4.

[10] Chun T Rim and Chris Mi. Wireless power transfer for electric vehicles and mobile devices. John Wiley \& Sons, 2017.

[11] M. Lu and K. D. T. Ngo. "Systematic Design of Coils in SeriesfffdfffdfffdSeries Inductive Power Transfer for Power Transferability and Efficiency". In: IEEE Transactions on Power Electronics 33.4 (Apr. 2018), pp. 3333-3345.

[12] W. Zhong and S. Y. R. Hui. "Maximum Energy Efficiency Operation of Series-Series Resonant Wireless Power Transfer Systems Using On-Off Keying Modulation". In: IEEE Transactions on Power Electronics 33.4 (Apr. 2018), pp. 3595-3603.

[13] Y. Jiang et al. "An optimal ZVS angle selection for constant current charging of EV's battery in series-series compensated wireless power transmission system”. In: 2018 IEEE Applied Power Electronics Conference and Exposition (APEC). Mar. 2018, pp. 1344-1349.
[14] Y. Jiang et al. "Analysis, Design and Implementation of WPT System for EV's Battery Charging based on Optimal Operation Frequency Range". In: IEEE Transactions on Power Electronics (2018), pp. 1-1.

[15] B. Yang et al. "Optimal parameters design for series series resonant converter for wireless power transfer". In: 2014 International Power Electronics and Application Conference and Exposition. Nov. 2014, pp. 772-777.

[16] J. Yin et al. "Front-End Monitoring of the Mutual Inductance and Load Resistance in a Series Series Compensated Wireless Power Transfer System". In: IEEE Transactions on Power Electronics 31.10 (Oct. 2016), pp. 7339-7352.

[17] F. Liu et al. "A phase-shift soft-switching control strategy for dual active wireless power transfer system". In: 2017 IEEE Energy Conversion Congress and Exposition (ECCE). Oct. 2017, pp. 2573-2578.

[18] Z. Yan et al. "Frequency Optimization of a Loosely Coupled Underwater Wireless Power Transfer System Considering Eddy Current Loss". In: IEEE Transactions on Industrial Electronics (2018), pp. 1-1.

[19] J. Lu et al. "Impedance Control Network Resonant DCDC Converter for Wide-Range High-Efficiency Operation". In: IEEE Transactions on Power Electronics 31.7 (July 2016), pp. 5040-5056. 